\title{
Fiber surface and electrical conductivity of electroless Ni-plated PET ultra-fine fibers
}

\author{
Woong-Ki Choi ${ }^{1}$, Byung-Joo Kim ${ }^{1}$ and Soo-Jin Park ${ }^{2,4}$ \\ ${ }^{1}$ R\&D Division, Korea Institute of Carbon Convergence Technology, Jeonju 561-844, Korea \\ ${ }^{2}$ Department of Chemistry, Inha Univ, Incheon 402-751, Korea
}

\section{Article Info}

Received 20 August 2013

Accepted 2 October 2013

*Corresponding Author

E-mail: sjpark@inha.ac.kr

Tel: $+82-32-860-7234$

\section{Open Access}

DOI: http://dx.doi.org/

10.5714/CL.2013.14.4.243

This is an Open Access article distributed under the terms of the Creative Commons Attribution Non-Commercial License (http://creativecommons.org/licenses/ by-nc/3.0/) which permits unrestricted non-commercial use, distribution, and reproduction in any medium, provided the original work is properly cited.

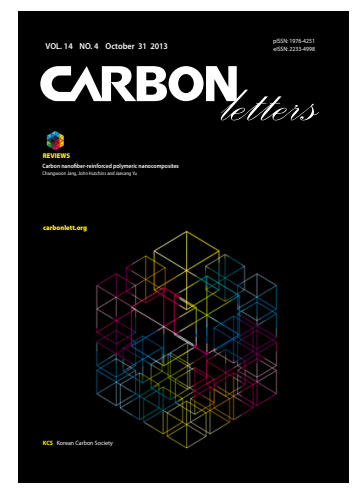

http://carbonlett.org

pISSN: $1976-4251$

elSSN: 2233-4998

Copyright $\odot$ Korean Carbon Society

\begin{abstract}
In this work, electroless Ni-plating on polyethylene terephthalate (PET) ultra-fine fibers surfaces was carried out to improve the electric conductivity of the fiber. The surface properties of PET ultra-fine fibers were characterized using scanning electron microscopy, X-ray diffraction, and contact angle analyses. The electric conductivity of the fibers was measured using a 4-point testing method. The experimental results revealed the presence of island-like nickel clusters on the PET ultra-fine fibers surfaces in the initial plating state, and the electric conductivity of the Ni-plated fibers was enhanced with increasing plating time and thickness of the Ni-layers on the PET ultra-fine fibers.
\end{abstract}

Key words: electroless Ni-plating, polyethylene terephthalate ultra-fine fibers, electric conductive

\section{Introduction}

With rapid development of the electronics industry, especially in the areas of personal computers and mobiles phones, the problem of electromagnetic interference (EMI) is increasing. One effective technique to address the EMI problem is to enhance the electrical conductivity of plastics by incorporating conductive fillers in the polymer matrix. Polymers generally are transformed to electrically conductive composites by either coating or compounding with conductive fillers, such as high electric conductivity fibers [1-6].

To increase the electrical conductivity of fibers, various metal coating techniques can be applied, such as, metal foil, conductive paint, sputter coating, vacuum deposition, flame, and electroless plating. Among them, electroless plating is generally the preferred means of obtaining a conductive filler for EMI shielding. This technique has advantages such as coherent metal deposition, excellent conductivity and shielding effectiveness, and applicability to non-conductors and can be applied to almost all fiber substances [4-8].

During electroless plating, fiber surfaces are metalized during exposure to plating solutions, coating molten salt in the presence of a reductant. The metal plating process is based on a redox reaction in which the reducing agent is oxidized and $\mathrm{Ni}^{2+}$ ions are reduced on the substrate surface. The first layer of deposited nickel serves as a catalyst for the process. As a result, there is typically a linear relationship between the coating thickness and time [5,7-10].

The objective of this study is to apply electroless nickel plating to the preparation of high conductive PET ultra-fine fibers and investigate the effects of electroless Ni-plating on the surface properties and electrical conductivity of PET ultra-fine fibers. 
Table 1. Composition and operating conditions of electroless $\mathrm{Ni}$ plating bath

\begin{tabular}{ccc} 
& $\mathrm{NiCl}_{2} \cdot 6 \mathrm{H}_{2} \mathrm{O}$ & $280 \mathrm{~g} / \mathrm{L}$ \\
& $\mathrm{Na}_{3} \mathrm{C}_{6} \mathrm{H}_{5} \mathrm{O}_{7} \cdot 1.5 \mathrm{H}_{2} \mathrm{O}$ & $15 \mathrm{~g} / \mathrm{L}$ \\
Composition & $\mathrm{NaH}_{2} \mathrm{PO}_{2} \cdot 2 \mathrm{H}_{2} \mathrm{O}$ & $100 \mathrm{~g} / \mathrm{L}$ \\
& $\mathrm{NH}_{4} \mathrm{Cl}$ & $100 \mathrm{~g} / \mathrm{L}$ \\
& $\mathrm{PbNO}_{3}$ & $30 \mathrm{~g} / \mathrm{L}$ \\
\hline \multirow{2}{*}{ Conditions } & $\mathrm{pH}$ & 8.25 \\
& Temperature $\left({ }^{\circ} \mathrm{C}\right)$ & $90 \pm 1$ \\
& Plating time (min) & $1-30$ \\
\hline
\end{tabular}

Table 2. Variation of the surface free energy by electroless $\mathrm{Ni}$ plated PET ultra-fine fibers

\begin{tabular}{cccccc} 
& $\begin{array}{c}\gamma_{\mathrm{S}} \\
\left(\mathrm{mJ} / \mathrm{m}^{2}\right)\end{array}$ & $\begin{array}{c}\gamma_{\mathrm{s}}{ }^{\mathrm{D}} \\
\left(\mathrm{mJ}^{2} / \mathrm{m}^{2}\right)\end{array}$ & $\begin{array}{c}\gamma_{\mathrm{s}}{ }^{\mathrm{P}} \\
\left(\mathrm{mJ} / \mathrm{m}^{2}\right)\end{array}$ & $\gamma_{\mathrm{s}}{ }^{+}$ & $\gamma_{\mathrm{s}}{ }^{-}$ \\
\hline As-received & 35.3 & 33.8 & 1.6 & 1.4 & 0.5 \\
Ni-plating & 37.2 & 28.8 & 8.4 & 7.0 & 1.4 \\
\hline
\end{tabular}

PET: polyethylene terephthalate .

\section{Experimental}

The fibers used in this work were polyethylene terephthalate (PET) fiber 130d/48f (Island-In Sea Type <separation 36>) manufactured by KOLON.

Alkali hydrolysis of PET fibers was accomplished by using $\mathrm{NaOH}\left(1 \mathrm{~N}, 80^{\circ} \mathrm{C}, 120 \mathrm{~min}\right)$. The electroless nickel plating was deposited on PET ultra-fine fiber of $10 \mathrm{~cm}$ length using nickel chloride as the source of nickel and sodium hypophophite as a reducing agent.

A two-step pretreatment consisting of sensitization and activation was used to catalyze the PET ultra-fine fibers. The sensitizer and activator were stannous chloride/hydrochloric acid and palladium chloride/hydrochloric acid, respectively, which assisted with the formation of a nucleus to plate the metal onto the surface of the PET ultra-fine fibers. The sensitized PET ultra-fine fibers were added to the solution containing the reducing agent. Nickel chloride was used as the source of metal ions, sodium hypophosphite was the reducing agent, and sodium citrate was used as a complexing agent to control the $\mathrm{pH}$ of the bath during the plating process. The electroless plating was performed on a hot plate with a magnetic stirrer while maintaining the temperature of the bath at $60 \pm 2{ }^{\circ} \mathrm{C}$. Samples were prepared at different plating times: Ni-5, 5 min; Ni-10, $10 \mathrm{~min}$; Ni-20, $20 \mathrm{~min}$; Ni-30, $30 \mathrm{~min}$. Table 1 lists the composition and conditions of the Ni plating in this work.

Wide-angle X-ray diffraction (XRD) patterns of Ni-plated PET ultra-fine fibers were obtained with a Rigaku Model D/ MAX-III B diffractometer equipped with a rotation anode and $\mathrm{CuK} \alpha$ radiation $(\lambda=0.15418 \mathrm{~nm})$ as the source for measuring the interlayer spacing, $d_{(002)}$. Changes in the surface morphology

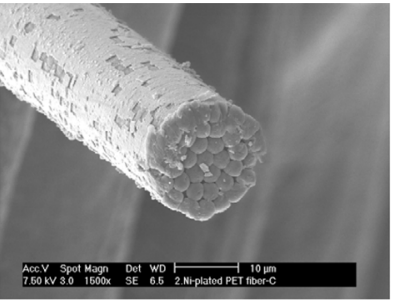

(a)

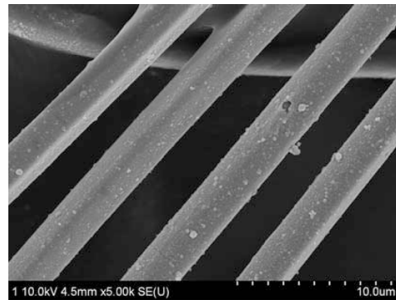

(b)
Fig. 1. Scanning electron microscopy photographs of polyethylene terephthalate ultramicrofibers. (a) Before separation with $\mathrm{NaOH}$, (b) after separation with $\mathrm{NaOH}$.

of Ni plated PET ultra-fine fibers were examined using scanning electron micrographs (SEM, JEOL JSM-840A).

The four-point method was used in the measurement of the conductivity of fiber bundles. Fiber bundles were cemented with silver paint to Pt leads that were printed onto an alumina plate. Silver paint was used in an effort to minimize measurement error. The electric resistivity of the PET ultra-fine fibers before and after Ni-plating was determined by measuring the volume resistivity using a digital multi-meter (MCP-T610, Mitsubishi Chemical Cooperation of Japan). The measuring room was maintained at a temperature of $25\left( \pm 2^{\circ} \mathrm{C}\right)$ and a relative humidity of $55( \pm 2 \%)$.

The contact angle was used as a parameter to characterize the wetting performance and surface free energy of the Ni-plated PET ultra-fine fibers. Contact angle measurements of PET ultrafine fibers were performed using a Krüss Processor Tensionmeter K100 with a fiber apparatus. Two grams of carbon fibers was packed into the apparatus, and then mounted indirectly to the measuring arm of the microbalance. The packing factor of the fibers was measured for each continuous filament by measuring the increase in weight per unit time at zero depth of immersion of a completely wetting test liquid (n-hexane). The wetting liquids used for contact angle measurements were water, diiodomethane, and ethyleneglycol. The surface free energy and the London dispersive and specific components of the fibers studied for the wetting liquids are listed in Table 2.

\section{Results and Discussion}

Fig. 1a shows SEM photographs of PET fibers. The as-received PET fibers had uniform diameters. Fig. 2b displays a SEM image of PET fibers after hydrolysis with $\mathrm{NaOH}$. Completely separated fiber can be observed.

Fig. 2 schematically illustrates the formation of nickel layers on PET ultra-fine fibers. Normally, electroless plating is achieved through the following three steps: 1) initial step: introduction of nuclei, 2) propagation step: formation of Ni islands, 3) layer formation step: formation of a perfect layer.

Fig. 3a shows SEM micrographs of the as-received PET ultra-fine fibers, revealing a smooth surface. Fig. 3 b displays SEM images of Ni-plated PET ultra-fine fibers after $30 \mathrm{~min}$. It was found that a perfect Ni-layer formed and fully covered the PET ultra-fine fiber surfaces.

Fig. 4 shows the thickness of the Ni-layer on the PET ultra- 


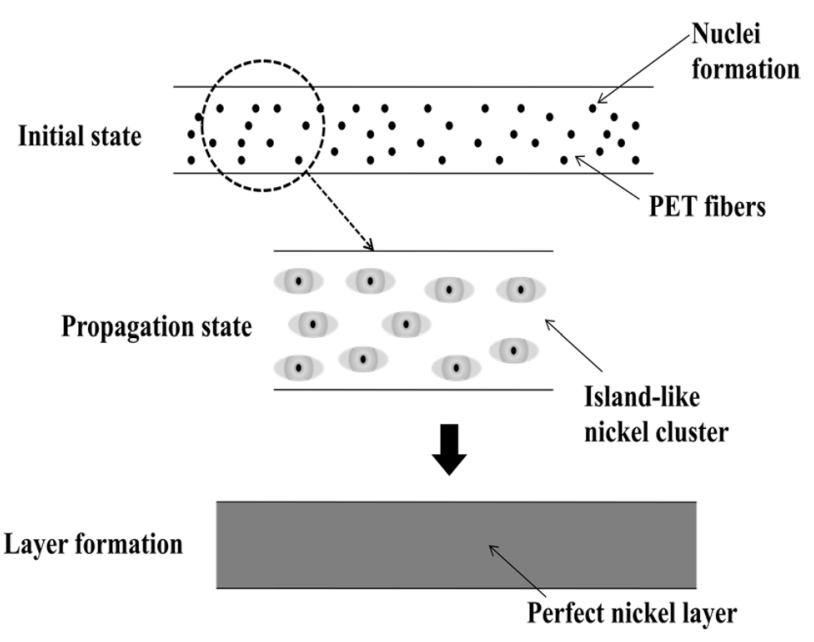

Fig. 2. Schematic diagram of Ni-plated polyethylene terephthalate (PET) ultramicrofibers.
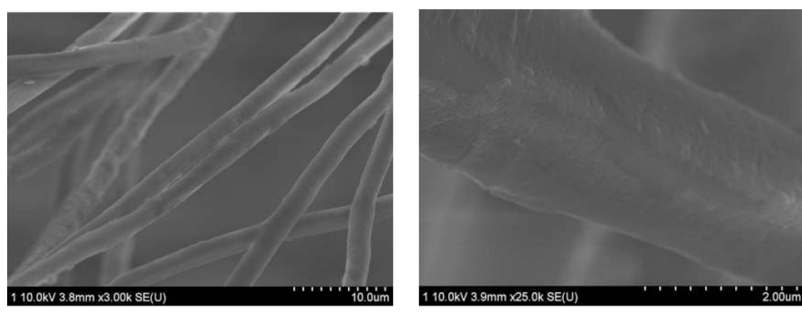

(a)
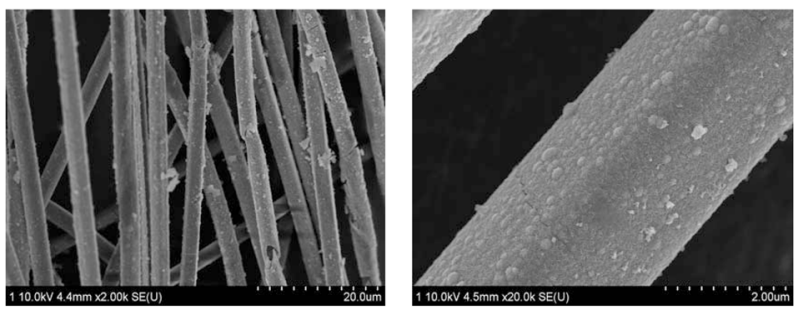

(b)

Fig. 3. Scanning electron microscopy images of Ni-plated polyethylene terephthalate ultramicrofibers. (a) As-received, (b) $30 \mathrm{~min}$.
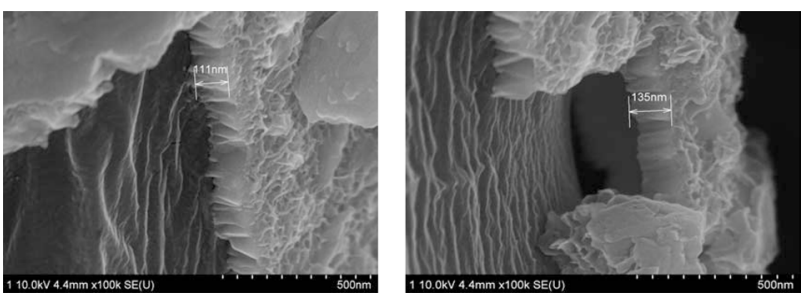

Fig. 4. The thickness of Ni-plated polyethylene terephthalate ultramicrofibers. (a) $5 \mathrm{~min}$, (b) $10 \mathrm{~min}$.

fine fibers as a function of the electroless plating time. This figure shows that the thickness of the Ni-layer increases with an increase in the plating time. The behavior of the thickness of the Ni-layer is in a good relationship with that of the plating time.

Fig. 5 shows the XRD patterns of Ni-plated PET ultra-fine fibers. It was found that the $\mathrm{Ni}(111)$ peak increased when the

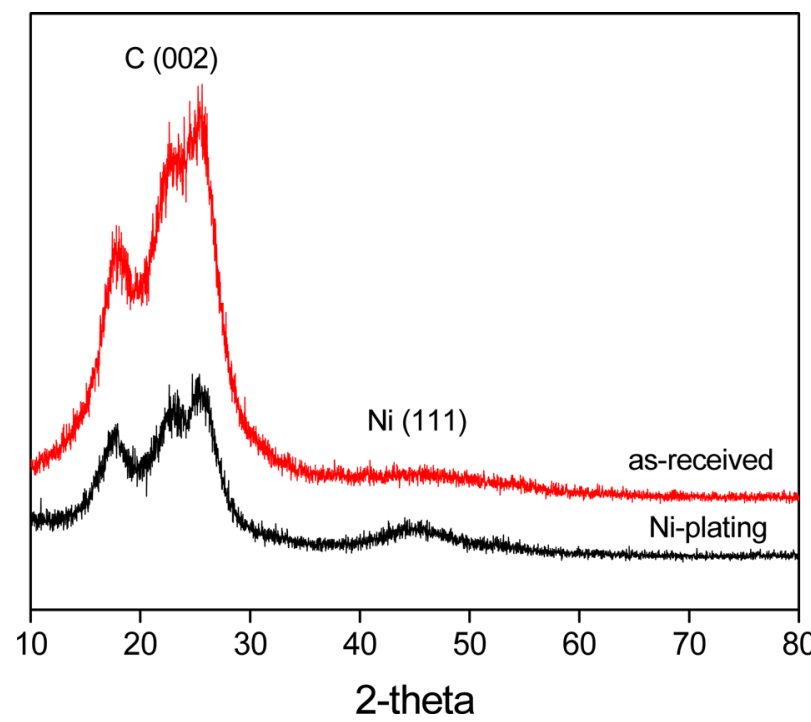

Fig. 5. X-ray diffraction of electroless Ni-plated polyethylene terephthalate ultramicrofibers.

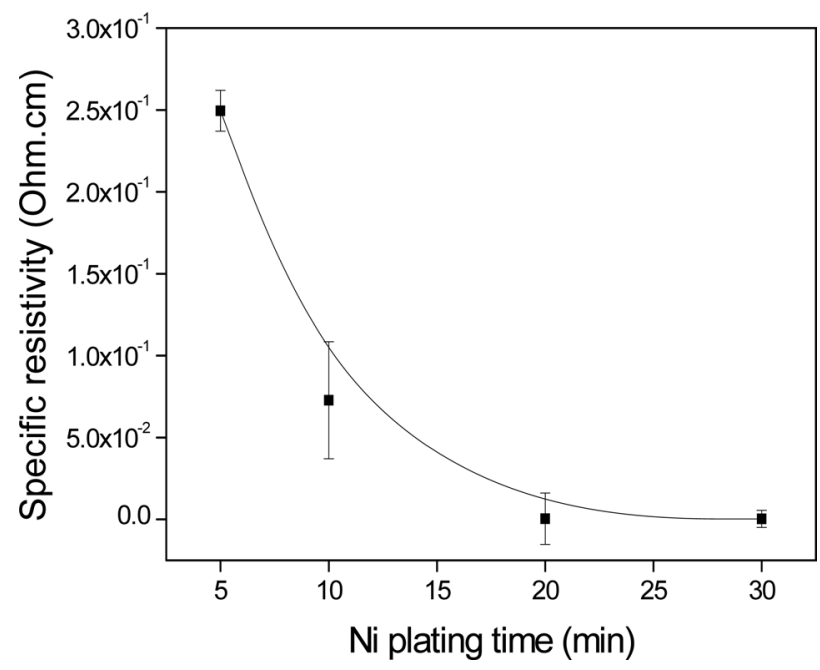

Fig. 6. Specific resistivity of Ni-plated polyethylene terephthalate ultramicrofibers as a function of Ni plating time.

fibers were plated with nickel. Meanwhile, the decrease of the $\mathrm{C}(002)$ peak upon plating the fibers with nickel indicated that metallic nickel formed a perfect layer and covered the outer surface of the PET ultra-fine fibers.

It is well known that precise contact angle measurement on fibrous materials is difficult, although several methods have been proposed. When a porous material, e.g., a powder of gel, is placed in contact with a liquid of lower surface tension, the liquid rises through the pore system with a velocity that is related to the mean size of the pores, as well as the surface tension and viscosity of the liquid. The relation between these quantities is given by the Washburn Eq. (1):

$$
\frac{\mathrm{m}^{2}}{\mathrm{t}}=\frac{\mathrm{c} \cdot \rho^{2} \cdot \gamma_{\mathrm{L}} \cdot \cos \theta}{\eta}
$$

where ' $\mathrm{m}$ ' is the weight of the penetrating liquid, ' $\mathrm{t}$ ' the flow 
time, ' $c$ ' the packing factor, and ' $\rho$ ' the density of measuring liquid. ' $\gamma_{\mathrm{L}}$ ' is the liquid surface tension and ' $\eta$ ' is the viscosity of the liquid.

The contact angles of non-treated and nickel-coated PET ultra-fine fibers were measured by three test liquids, water, diiodomethane, and ethylene glycol. In addition, the surface free energy, London dispersive components, and polar components of the PET ultra-fine fibers studied are given in Table 2. The polar component, $\gamma_{\mathrm{s}}{ }^{\mathrm{p}}$ of the Ni-plated PET ultra-fine fibers is increased. However, the dispersive component $\gamma_{\mathrm{S}}{ }^{\mathrm{L}}$ is decreased. These results reveal that the surface polarity increases compared to the as-received PET ultra-fine fibers.

Fig. 6 shows the specific resistivity of the electroless Ni-plated PET ultra-fine fibers with respect to the plating time. It was observed that the electrical conductivity increased with increasing plating time. It was also found that the electric conductivity was significantly enhanced up to $20 \mathrm{~min}$, after which no additional enhancement occurred, up to $30 \mathrm{~min}$. This was most likely due to the formation of perfect Ni layers on the PET ultra-fine fibers after a specific point of the process.

\section{Conclusions}

In this work, nickel electroless plating on PET ultra-fine fibers was carried out to improve the electric conductivity of the fibers. The following conclusions can be drawn from this study: 1) the presence of $\mathrm{Ni}$ can introduce high electric conductivity to PET ultra-fine fibers; and 2) electrical conductivity of Ni-plated PET ultra-fine fibers increased with increasing plating time and thickness of the Ni-layers.

\section{References}

[1] Dhawan SK, Singh N, Venkatachalam S. Shielding effectiveness of conducting polyaniline coated fabrics at $101 \mathrm{GHz}$. Synth Met, 125,
389 (2001). http://dx.doi.org/10.1016/S0379-6779(01)00478-7.

[2] Kim WM, Ku DY, Lee IK, Seo YW, Cheong BK, Lee TS, Kim IH, Lee KS. The electromagnetic interference shielding effect of indiumzinc oxide/silver alloy multilayered thin films. Thin Solid Films, 473, 315 (2005). http://dx.doi.org/10.1016/j.tsf.2004.08.083.

[3] Chen CS, Chen WR, Chen SC, Chien RD. Optimum injection molding processing condition on EMI shielding effectiveness of stainless steel fiber filled polycarbonate composite. Int Commun Heat Mass Transf, 35, 744 (2008). http://dx.doi.org/10.1016/j.icheatmasstransfer.2008.02.006.

[4] Zhao X, Hirogaki K, Tabata I, Okubayashi S, Hori T. A new method of producing conductive aramid fibers using supercritical carbon dioxide. Surf Coat Technol, 201, 628 (2006). http://dx.doi. org/10.1016/j.surfcoat.2005.12.021.

[5] Abdel Gawad O, Abou Tabl MH, Abdel Hamid Z, Mostafa SF. Electroplating of chromium and $\mathrm{Cr}$-carbide coating for carbon fiber Surf Coat Technol, 201, 1357 (2006). http://dx.doi.org/10.1016/j. surfcoat.2006.02.001.

[6] Murashita T. Conductive transparent fiber probes for shear-force atomic force microscopes. Ultramicroscopy, 106, 146 (2006). http://dx.doi.org/10.1016/j.ultramic.2005.06.061.

[7] Park SJ, Jang YS, Rhee KY. Interlaminar and ductile characteristics of carbon fibers-reinforced plastics produced by nanoscaled electroless nickel plating on carbon fiber surfaces. J Colloid Interface Sci, 245, 383 (2002). http://dx.doi.org/10.1006/jcis.2001.8040

[8] Kim S, Park SJ. Electrical signal effect on electrochemical activities of metal catalysts electrically deposited on carbon nanotubes. Electrochim Acta, 53, 4082 (2008). http://dx.doi.org/10.1016/j. electacta.2007.08.067

[9] Park SJ, Kim BJ, Lee YS, Cho MJ. Influence of copper electroplating on high pressure hydrogen-storage behaviors of activated carbon fibers. Int J Hydrogen Energy, 33, 1706 (2008). http://dx.doi. org/10.1016/j.ijhydene.2008.01.011

[10] Park SJ, Jin SY, Effect of nickel electroplating on HCI removal efficiency of activated carbon fibers. J Ind Eng Chem (Korea), 11, 395 (2005). 